\title{
Resenha
}

\section{Cultura e saúde nas organizações ${ }^{1}$}

\section{Culture and health in the organizations}

\author{
Izabel Carolina Martins CAMPOS ${ }^{2,3}$ \\ Flávia de Novaes COSTA ${ }^{3,4}$
}

Para Tamayo et al. (2004), o trabalho humano, observado sobre o prisma histórico, revela sua transformação num meio civilizado e de cultura, marcando os mais remotos lugares com o sinal do homem. $\mathrm{O}$ trabalho representa para a pessoa um dos aspectos mais relevantes de sua vida e é inseparável da sua existência. Esse trabalho não é só a produção de bens e riquezas, mas a maneira de sua realização como pessoa. A relação entre o trabalho e o bem-estar do trabalhador requer a implantação e implementação, por parte das organizações, de políticas de prevenção, construindo uma cultura organizacional, em que seja propícia a realização da missão da organização com a garantia da qualidade de vida e a realização das pessoas.

Na sociedade contemporânea, o trabalho ocorre nas organizações, ou seja, está situado em um contexto pré-determinado. O livro analisa o fato de que cada organização tem uma cultura voltada para a produtividade, e, em certos casos, a meta do lucro prevalece em detrimento da realização das pessoas. A cultura favorece o processo de personalização ou despersonalização do indivíduo.

Para os autores, o homem dedica boa parte de sua existência ao trabalho e o aparecimento de doenças pode estar associado aos impactos da organização do trabalho sobre a saúde, o bem-estar físico, mental e social dos trabalhadores. O conceito de saúde organizacional está diretamente associado ao equilíbrio entre a estrutura, o funcionamento organizacional e o bem-estar individual.

A cultura é um substrato de uma organização e, talvez, um de seus fundamentos. As organizações são um modo de produção social, de agrupamento de pessoas em torno do trabalho para produzir riquezas, bens, mercadorias e cultura. A cultura está relacionada ao modo de produção social do trabalho, é um componente envolvente, onipresente e invisível na organização e pode ser também visível ou concreta no modo como as pessoas se vestem, se comunicam, se organizam, como criam instrumentos de manipulação de artefatos humanos no trabalho.

É invisível quando se expressa em processos subliminares, como a comunicação não verbal, a interação, o conflito, a competição, a assimilação ou os processos subjetivos.

A cultura é altamente benéfica quando favorece o prazer e a realização do trabalhador, e maléfica quando

$\boldsymbol{\nabla} \mathbf{\nabla} \boldsymbol{\nabla}$

1 TAMAYO, A. et al. (Orgs.). (2004). Cultura e saúde nas organizações. São Paulo: Artmed.

2 Universidade Federal de Santa Catarina, Programa de Pós-Graduação em Psicologia. Florianópolis, SC, Brasil.

3 Governo do Estado de Santa Catarina, Secretaria de Estado da Administração. R. Major José Augusto de Faria, 113, Centro, 88020-140, Florianópolis, SC, Brasil. Correspondência para/Correspondence to: I.C.M. CAMPOS. E-mail:<izabel@sea.sc.gov.br>, <lzacarol2004@yahoo.com.br>.

4 Tribunal de Justiça de Santa Catarina. Florianópolis, SC, Brasil. 
nega a identidade e a realização profissional e pessoal desse trabalhador e gera sofrimento, sobrecargas físicas e emocionais invariavelmente relacionadas ao desencadeante de agravos à saúde, como as lesões por esforços repetitivos, distúrbios osteomusculares relacionados ao trabalho, stress, esgotamento profissional ou burnout, depressão e distúrbios psicossomáticos. O conhecimento da cultura organizacional favorece o entendimento de como vivem e por que adoecem os trabalhadores.

Para Tamayo et al., há uma relação simbiótica entre a constituição do ser humano, o processo civilizatório e a produção do trabalho, o que pode ser denominado de marcas da cultura.

O trabalho é um dos elementos da própria cultura humana, talvez um dos mais importantes, gerador de bens e riquezas, mas também de agravos à saúde das pessoas. Para os autores a organização do trabalho deve garantir às pessoas prazer, satisfação profissional, sua realização e sua permanente aspiração à felicidade.

O livro é organizado em três partes, com o total de dez capítulos, e escrito por pesquisadores e consultores do campo da Psicologia Organizacional e do Trabalho. A primeira, intitulada "Conceitos básicos", tem como principal objetivo introduzir o leitor no mundo conceitual da cultura e da saúde no trabalho. Paz e Tamayo se referem a conceitos básicos acerca do perfil cultural das organizações, apresentam uma visão geral de cultura organizacional bem como uma proposta inovadora e eficiente para gestão e análise de dimensões culturais da empresa.

Mendes e Cruz, no Capítulo "Trabalho e saúde no contexto organizacional: algumas vicissitudes teóricas", apresentam uma reflexão acerca da diversidade de estudos de saúde-adoecimento no contexto das organizações (stress, burnout, bem-estar, prazer-sofrimento). Os autores discutem diferentes abordagens da Medicina do Trabalho, da Medicina Social, da Psicologia Social, do Trabalho, e Organizacional, da Ergonomia e da Psicodinâmica. Analisam cuidadosamente variáveis referentes aos indicadores de saúde; - o prazer, satisfação e bem-estar no trabalho - e referentes aos indicadores de adoecimentos; - o sofrimento, stress e esgotamento profissional (burnout). Também tratam da relação entre os indicadores saúde-adoecimento, destacando dentre os transtornos relacionados ao trabalho os distúrbios musculoesqueléticos e a depressão.

A segunda parte do livro, intitulada "Fatores culturais e saúde", é dividida em cinco capítulos, onde é analisada a relação entre algumas dimensões culturais da organização e saúde no trabalho. Mendes discute aspectos da relação entre cultura e saúde no trabalho, considera estratégias de enfrentamento do sofrimento e de busca do prazer bem como o papel da cultura no processo de adoecimento ou de promoção à saúde dos indivíduos nas organizações.

A presença de fenômenos como stress e gestão das emoções no trabalho são fatores que, segundo Mendes, favorecem o aparecimento de processos de adoecimento, implicando uma dinâmica de forças, por vezes contraditórias, dos atores da organização que pretendem garantir a saúde e a produtividade.

Como a própria autora afirma, a "cultura organizacional e prazer-sofrimento no trabalho: uma abordagem psicodinâmica" apresenta uma visão do binômio prazer-sofrimento como indicador de saúde no trabalho. Finaliza integrando os achados empíricos à teoria e aponta algumas contribuições práticas desses estudos para a gestão de pessoas.

Tamayo, Lima e Silva discutem os aspectos referentes ao "clima organizacional e stress no trabalho". Esclarecem a relação entre cultura e clima organizacional, bem como o impacto desse último sobre o stress ocupacional. Conceitos básicos de clima organizacional e stress são analisados e esclarecidos, bem como as relações entre essas duas variáveis tanto do ponto de vista empírico quanto teórico. Os resultados demonstram que o ambiente é o indicador de quão eficiente é a organização na valorização dos seus recursos humanos.

Ferreira e Assmar analisam no Capítulo "Cultura, satisfação e saúde nas organizações" as implicações da cultura organizacional na satisfação e na saúde do trabalhador. Realizam uma revisão dos principais pressupostos teóricos associados a cada uma delas e discutem estudos empíricos sobre as relações entre essas variáveis. As autoras propõem um modelo integrado de cultura, satisfação e saúde no trabalho e demonstram as possibilidades de aplicação desse modelo em pesquisas e em intervenção (aplicação prática) em projetos de saúde do trabalhador. 
Paz no capítulo "Poder e saúde organizacional" demonstra que há uma relação bastante evidente entre poder e saúde. A autora discute quais são as características das estruturas de relação de poder e dominação de uma organização que implicam os processos de saúde no trabalho. Alguns aspectos dessas estruturas de dominação de poder podem ser observados na forma como estão configurados nos estilos, nos jogos políticos, na natureza dos intercâmbios, nas negociações, no jeito de gerir. Todos esses aspectos influenciam os processos de gratificação e satisfação do trabalho.

A autora também discute como ocorre o equilíbrio nas relações interpessoais para garantir a saúde do trabalhador nas organizações. Ressalta a estrutura das organizações em suas configurações de poder, com seus estilos de dinâmica e jogos políticos como característicos do funcionamento das organizações; as vivências de gratificação e desgosto; e o bem-estar dos trabalhadores.

Em"Cultura, justiça e saúde no trabalho", Assmar e Ferreira exploram as relações de justiça, cultura organizacional e saúde bem como examinam suas implicações no stress psicológico e na qualidade de vida no trabalho. Fazem uma breve revisão de estudos sobre justiça organizacional e as diferentes formas como se manifesta no trabalho. Destacam o impacto dos valores culturais dos trabalhadores nas percepções de injustiça, enfatizando as reações emocionais negativas daí resultantes e os prejuízos que acarretam à saúde dos trabalhadores e das próprias organizações.

A terceira e última parte do livro, intitulada "Gestão do trabalho e saúde", aborda reflexões acerca do "Bem-estar: equilíbrio entre a cultura do trabalho prescrito e a cultura do trabalho real". Ferreira descreve e analisa questões referentes à relação da especificidade das situações efetivas de trabalho e a concepção das tarefas nas organizações. O trabalho prescrito nas organizações permite depreender as práticas, os valores, os hábitos e a gestão das tarefas. Os trabalhadores buscam permanentemente gerir a discrepância entre o trabalho prescrito e o trabalho real com vistas à garantia de seu bem-estar e à qualidade dos produtos ou serviços.

Abrahão e Santos abordam "O controle no trabalho: os seus efeitos no bem-estar e na produ- tividade". Demonstram a contextualização das centrais de atendimento, as condições de trabalho dos atendentes, e o impacto da informatização na saúde desses trabalhadores. Concluem que há perversidade do trabalho nas centrais de atendimento, uma vez que por meio do controle os dirigentes alimentam um sistema de punição em vez de reinvestirem na adequação do modo de gestão.

Cruz complementa as reflexões com aspectos referentes ao aparecimento de "Distúrbios musculoesqueléticos nos processos de trabalho e cultura organizacional". Relaciona indicadores da esfera emocional, stress e burnout como aspectos relevantes para o diagnóstico de lesões por esforços repetitivos (LER) e distúrbios osteomusculares relacionados ao trabalho (DORT). Avalia aspectos mediadores que a cultura organizacional proporciona sobre condutas saudáveis e patológicas no ambiente de trabalho. 0 autor, em sua análise, destaca os processos cognitivos, condições de salubridade, ambientais e sociais, no diagnóstico das situações de trabalho e no tratamento de variáveis ligadas ao trabalho e à cultura organizacional.

A leitura do livro, em geral, fornece possibilidade de reflexão sobre prazer e sofrimento no trabalho, e situa a relação direta com saúde e cultura da organização. Associa, paradoxalmente, prazer e sofrimento. Ao realizar o trabalho, sentimentos e emoções estão presentes no trabalhador, permeados pela cultura da organização: prazer de realizar o trabalho e angústia em executá-lo sem as condições necessárias, ansiedade por correr riscos, ocultar informações importantes, medo de ser responsável por resultados indesejados, ou mesmo responder com processo de adoecimento (depressão, LER/DORT, burnout, etc.).

O papel desempenhado pela cultura organizacional tem auxiliado o processo de formação e manutenção dos sentimentos que o indivíduo nutre por seu trabalho e pela organização.

O livro aborda a relação entre saúde, sofrimento psíquico e cultura da organização. A relação entre os sujeitos é que pode gerar conflitos, competição, estratégias de defesa, tudo inserido num contexto permeado por valores, cultura, produtividade, trabalho prescrito e trabalho real. A realização dos sujeitos, a 
renda familiar, a satisfação de suas necessidades básicas são relevantes no contexto organizacional.

O entendimento do prazer e do sofrimento gera avanços na investigação e formulação de estratégias coletivas de defesa específica no contexto da cultura organizacional.

A insatisfação e os problemas de saúde vivenciados no trabalho interferem na rotatividade, no absenteísmo e na produtividade da organização, acarretando perda de bons profissionais, despesas adicionais com seleção e recrutamento, e outros desdobramentos na eficácia da organização. Nesse sentido, todos os dirigentes precisam desenvolver e manter uma cultura saudável que assegure a satisfação, a saúde e o bem-estar dos indivíduos.

Os autores destacam com clareza o papel do trabalho e o prazer, a satisfação e o sofrimento vivenciados pelos trabalhadores, as repercussões em sua saúde e na qualidade de vida no trabalho.

Em síntese, o livro é organizado por cientistas de diferentes regiões do país e objetiva fornecer aos leitores o conhecimento dos assuntos de forma desencadeada. Os autores informam os temas relevantes para o avanço no conhecimento de interesse da Psicologia Organizacional e do Trabalho. A relação entre cultura e saúde nas organizações discute e abre horizontes para os profissionais da área da saúde e do trabalho.

O livro atende expectativas de profissionais que atuam na área bem como preenche uma lacuna de pesquisa sobre a relação entre saúde e cultura nas organizações. A edição dessa obra contribui para o avanço do conhecimento científico sobretudo de professores, estudantes de Psicologia e demais profissionais que atuam no campo da saúde. Fornece a possibilidade de aprimoramento de teorias para a intervenção na realidade da cultura e saúde organizacionais.

Recebido em: 5/10/2005

Versão final reapresentada em: 9/2/2006

Aprovado em: 16/6/2006 